\title{
BMJ Open Influence of COVID-19 on the preventive health behaviours of Indigenous Peoples of Australia residing in New South Wales: a mixed- method study protocol
}

\author{
Kim Usher (1) , ${ }^{1}$ Navjot Bhullar (1D , , David Sibbritt (i) , ${ }^{3}$ \\ Suruchi Sue Anubha Amarasena, ${ }^{4}$ Wenbo Peng (D) , 3 Joanne Durkin (D) , ${ }^{1}$ \\ Reakeeta Smallwood (D) , ${ }^{5}$ Tamara Power (D) , ${ }^{6}$ Cheryl Porter, ${ }^{4}$ Debbie McGowen, ${ }^{7}$ \\ Debra Jackson (iD ${ }^{6}$
}

To cite: Usher $\mathrm{K}$, Bhullar $\mathrm{N}$, Sibbritt $\mathrm{D}$, et al. Influence of COVID-19 on the preventive health behaviours of Indigenous Peoples of Australia residing in New South Wales: a mixed-method study protocol. BMJ Open 2021;11:e047404. doi:10.1136/ bmjopen-2020-047404

- Prepublication history for this paper is available online. To view these files, please visit the journal online (http://dx.doi. org/10.1136/bmjopen-2020047404).

Received 10 December 2020 Accepted 10 September 2021

Check for updates

(c) Author(s) (or their employer(s)) 2021. Re-use permitted under CC BY-NC. No commercial re-use. See rights and permissions. Published by BMJ.

For numbered affiliations see end of article.

Correspondence to

Joanne Durkin;

jdurkin3@myune.edu.au

\begin{abstract}
Introduction Chronic conditions impact Indigenous Peoples of Australia at a much higher rate than non-Indigenous Australians. Attendance at the Medicare Benefits Scheme (MBS) supported Indigenous health checks are crucial to improve prevention and management of chronic health conditions. However, in conjunction with lifestyle and environmental factors, attendance rates at primary healthcare services for screening and treatment have fallen in Australia during the COVID-19 pandemic. This study aims to explore the influence of the COVID-19 pandemic on preventive health behaviours of Indigenous Australians and the associated barriers to, and enablers of, engagement with health services to formulate a targeted intervention strategy.

Methods and analysis A concurrent mixed-methods study (comprising quantitative and qualitative data collection methods) will be employed. Descriptive analysis of MBS data about the characteristics of Indigenous Peoples of Australia claiming health assessment services will be performed. Generalised estimating equation regression models will be used to examine the use of health assessment services over time. Qualitative interviews informed by Indigenous research methods will be conducted. Interviews will investigate barriers to, and enablers of, engagement with health services. Thematic

Strengths and limitations of this study

- A strength of this study is that it combines large data and yarning story-telling with Indigenous People to provide an in-depth explanation of current preventive behaviours during isolation, identify barriers and enablers of health-seeking behaviours in regard to preventive health programmes, and outline potential strategies to improve health behaviours and attendance at preventive programmes in the future.

- Ongoing and authentic engagement with Indigenous communities to ensure findings are meaningful and relevant to community.

- Not all Indigenous Australians are enrolled on the Medicare Benefits Scheme (MBS) (Medicare) database via the Voluntary Indigenous Identifier. Therefore, our findings may underestimate the health services utilisation of Indigenous Australians pre-COVID-19 and during COVID-19 pandemic.

- MBS claims data are limited to medical services subsidised by the Australian government such as general practitioner and allied health services. Thus, other health services used by Indigenous Australians were not included in our project.
\end{abstract} approach guided by the principles of indigenist praxis, storytelling and collaborative research will be used to analyse the interview data. The project commenced in July 2020 and will be completed by July 2022 .

Ethics and dissemination The project received ethics approval from the Aboriginal Health and Medical Research Council of New South Wales and the University of New England Human Research Ethics Committee. Findings will be disseminated via peer-reviewed journal articles, conferences, government and relevant stakeholder reports, and infographics.

\section{INTRODUCTION}

Indigenous Peoples of Australia are prone to chronic health conditions. ${ }^{1}$ In conjunction with lifestyle and environmental factors, this increases the risk to Indigenous Peoples contracting COVID-19, ${ }^{2}$ as evidenced by poor outcomes in previous pandemics. ${ }^{3}$ Unfortunately, Indigenous Peoples generally have lower rates of access to preventive health opportunities, ${ }^{4}$ and the research team experience indicates that these rates have decreased as a result of COVID-19, similar to that seen in non-Indigenous Peoples of Australia. Attendance rates at primary healthcare services for screening and treatment have fallen in Australia during the COVID-19 pandemic and people are less likely to see their doctor for any non-urgent health-related activity. ${ }^{5}$ 
Many Indigenous Peoples have multiple underlying chronic conditions and greater susceptibility to, and poorer outcomes from infectious diseases. Aboriginal Controlled Health Services have led the way in ensuring Indigenous People of Australia are adequately serviced during the pandemic.

Understanding barriers to engaging in preventive health behaviours and attendance at health services due to COVID-19 in this group will help in developing and implementing specific intervention strategies to improve engagement with preventive health services. The present study will explore the influence of COVID-19 on the preventive health behaviours of Indigenous Peoples, residing in New South Wales (NSW), Australia and provide an in-depth explanation of the preventive behaviours during isolation; identify barriers to, and enablers of, health-seeking behaviours in regard to preventive health programmes; and outline potential strategies to improve health behaviours and attendance at preventive programmes in the future.

\section{Aim of the study}

This study aims to explore the influence of the COVID-19 pandemic on preventive health behaviours and the associated engaging barriers to, and enablers of, engagement with health services.

\section{Research questions}

What are the pre-COVID-19 and during COVID-19 levels of preventive health behaviours, and what are the barriers to, and enablers of, preventive health behaviour service utilisation by Indigenous Peoples residing in NSW?

\section{METHODS}

\section{Study design and procedure}

A concurrent mixed-methods study (comprising quantitative and qualitative data collection methods) will be employed. Descriptive and multivariate analyses of the National Medicare Benefits Scheme (MBS) data about the characteristics of Indigenous Peoples of Australia claiming health assessment services and service utilisation will be performed, respectively. Qualitative interviews informed by Indigenous research methods will be conducted to explore the barriers to, and enablers of, engagement with health services.

The study sample for phase 1 is patients recorded in the MBS dataset, restricted to those who identify as Aboriginal and Torres Strait Islander People residing in NSW regardless of age. The collection of MBS data for 2020 and 2021 has not been completed. Therefore, the number of patients for which MBS data are held for this study is unknown. According to the latest report from the Australian Institute of Health and Welfare (AIHW), there were 66752 Indigenous Peoples in NSW who had at least one Indigenous-specific health check in 2017-2018. ${ }^{1}$ For phase 2, 15-20 qualitative interviews will be conducted at each of the four participating sites using purposive sampling. Therefore, our aim is to recruit 80 participants (20 participants at each site $\times 4$ sites). This sample size is based on sample guidelines from previously conducted, similar studies ${ }^{67}$ and advice from the Aboriginal advisory committee. The project commenced in July 2020 and will be completed by 31 July 2022 .

\section{Patient and public involvement}

The research project, research question and outcome measures and the use of associated methods were designed in consultation with the Aboriginal Advisory Council in Tamworth, NSW, Australia. Further, this research is designed in consultation with Aboriginal Controlled Health Services (Walhallow Aboriginal Health Corporation and Armajun Aboriginal Health Service). Dissemination of the results will include a range of strategies aimed to meet the needs of Aboriginal Corporations and service providers, primary healthcare providers, members of the community, Local Health Districts, policy-makers influencing government and non-government health services as well as an academic audience. They will include information packs, short videos, posters, social media advertising, presentations, workshops and academic papers.

\section{Ethics and dissemination}

The project has approval from the Aboriginal Health and Medical Research Council of NSW (AH\&MRC of NSW) and the University of New England Human Research Ethics Committee. Findings will be disseminated via peer-reviewed journal articles, conferences, government and relevant stakeholder reports, and infographics.

\section{Data analysis}

Phase 1 quantitative data analysis

The statistical analyses of the MBS data include two components: (1) descriptive analyses of the characteristics of Indigenous Peoples of Australia claiming health assessment services; (2) examination of the use of health assessment services over time, using statistical control charts and multivariable generalised estimating equation (GEE) regression models.

Descriptive analyses will include identifying the demographic characteristics of the Indigenous Peoples who have claimed health services- which will be examined before and during the COVID-19 pandemic lockdown period. These cross-sectional analyses will use statistical methods including Student's t-tests, analysis of variance, $\chi^{2}$ tests and logistic regression. Statistical control charts will be constructed to examine the trend of changes in the count of health services among Indigenous Peoples pre-COVID-19 and during the COVID-19 pandemic. Multivariable GEE regression models will be used to conduct longitudinal analyses, examining the use of health services including both health assessments and telehealth services/video consultation over time, taking 
into account potentially repeated use of these services by individuals. To control potential confounding in analyses, covariates include the variables ascertained via the MBS data including sociodemographic characteristics and clinical factors. We will adjust the models for the effects of all covariates. Statistical significance is set at $\mathrm{p}<0.05$. All analyses will be undertaken with Stata (V.16).

\section{Phase 2 qualitative data analysis}

Analysis of data will be conducted by the research team in collaboration with partners and participants, using a thematic approach guided by the principles of indigenist praxis, storytelling and collaborative research. The analytical process will be informed by thematic analysis ${ }^{8}$ and ongoing consultation with cultural advisory committee members. This process recognises the way in which collective reflexivity is embedded into the process of meaning making and how this is interpreted through the addition of based meaning. ${ }^{9}$ Storytelling analytical processes will also be used. ${ }^{10}$ Following analysis, findings will be taken back to the community for the purpose of developing strategies to inform practice and the possible development of hypotheses for future studies.

\section{Study outcomes}

Regarding phase 1 , the primary outcome measure is the health assessment services (eg, consultations and procedures) of Indigenous Peoples provided by primary care practitioners between January 2019 to December 2021. The secondary outcomes are the use of corresponding telehealth services and video consultations of these health assessment services.

Phase 2 outcomes will include a comprehensive understanding of the barriers to, and enablers of, engagement with preventive health checks and strategies to be developed and implemented to improve participation in preventive health behaviours of Indigenous Peoples residing in NSW.

\section{DISCUSSION}

The analysis of MBS data will identify the patterns of uptake of Indigenous Health Assessment checks during COVID-19 which will help to indicate whether there is the need for targeted strategies to improve rates of attendance in certain locations. The qualitative results will provide participants perspectives of the impact of COVID-19 on their attendance at preventative health appointments, barriers and difficulty to access and suggestions for improvements. Health prevention can lead to early detection of issues that are potentially treatable. Given the high level of chronic illness in Indigenous Peoples of Australia, it is important to understand behaviours related to health prevention behaviours. However, it is increasingly recognised that there are little data in this area related to Indigenous People of Australia. This research project will result in evidence that can be used in the primary care setting to understand the impact of COVID-19 on Indigenous clients, to determine barriers and enablers of access to preventive health services, and to develop strategies to improve access to health prevention services where needed.

\section{Study status}

To date, we have submitted the ethics application to obtain the MBS data for phase 1 , and received ethical approval from the AH\&MRC NSW for phase 2 interviews.

\section{Author affiliations}

${ }^{1}$ School of Health; Faculty of Medicine and Health, University of New England, Armidale, New South Wales, Australia

${ }^{2}$ School of Psychology; Faculty of Medicine and Health, University of New England, Armidale, New South Wales, Australia

${ }^{3}$ School of Public Health; Faculty of Health, University of Technology, Sydney, New South Wales, Australia

${ }^{4}$ Walhallow Aboriginal Health Service, Quirindi, New South Wales, Australia

${ }^{5}$ School of Nursing and Midwifery, University of Technology, Sydney, New South

Wales, Australia

${ }^{6}$ Susan Wakil School of Nursing and Midwifery; Faculty of Medicine and Health, The University of Sydney, Sydney, New South Wales, Australia

${ }^{7}$ Armajun Aboriginal Health Service, Armidale, New South Wales, Australia

Twitter Navjot Bhullar @DrNavjotBhullar, Joanne Durkin @ joanne_durkin and Tamara Power @TamaraJPower

Acknowledgements We acknowledge and celebrate the cultural diversity of all Aboriginal and Torres Strait Islanders peoples and pay respect to Elders past, present and future. We recognise their continuing connection to land, waters and culture. The authors wrote this article on the lands of the Anaiwan peoples of the Armidale area, the Gamilaroi peoples of Tamworth and Quirindi area, the Barwon, Bundarra, Balonne, and upper Hunter rivers and Liverpool plains area, the Gundungurra people, Gadigal and Dharug Peoples of the Blue Mountains, Sydney and Western Sydney. Hereafter, throughout this paper, when referring to the diverse First Nations Peoples of this great land, we use the term Indigenous for brevity.

Contributors KU, DJ and NB conceptualised and secured funding for the research study. KU, NB, WP, RS, TP, DS, and JD contributed to the application to the local ethics committee. KU, NB, SSAA, WP, DS and JD contributed to the application for data to support this study. $\mathrm{KU}$ and NB wrote the first draft of this protocol with contributions from DJ, WP, SSAA, JD, CP, RS, TP and DM. CP, RS, TP and DM provided specific cultural guidance on this protocol and project. All authors read and approved the final manuscript.

Funding This research is funded by the New South Wales (NSW) Health. NSW Government of Australia. Round 1 COVID-Grant Impact of COVID-19 on Indigenous Australians' preventive health behaviours: A mixed-methods study. University of New England. 2020. Grant Number: N/A.

\section{Competing interests None declared.}

Patient and public involvement The research project, research question and outcome measures and the use of associated methods were designed in consultation with the public.

Patient consent for publication Not applicable.

Provenance and peer review Not commissioned; externally peer reviewed.

Open access This is an open access article distributed in accordance with the Creative Commons Attribution Non Commercial (CC BY-NC 4.0) license, which permits others to distribute, remix, adapt, build upon this work non-commercially, and license their derivative works on different terms, provided the original work is properly cited, appropriate credit is given, any changes made indicated, and the use is non-commercial. See: http://creativecommons.org/licenses/by-nc/4.0/.

ORCID iDs

Kim Usher http://orcid.org/0000-0002-9686-5003

Navjot Bhullar http://orcid.org/0000-0002-1616-6094 
David Sibbritt http://orcid.org/0000-0003-3561-9447

Wenbo Peng http://orcid.org/0000-0001-9747-2466

Joanne Durkin http://orcid.org/0000-0001-9948-4794

Reakeeta Smallwood http://orcid.org/0000-0002-4586-8925

Tamara Power http://orcid.org/0000-0002-3334-0322

Debra Jackson http://orcid.org/0000-0001-5252-5325

\section{REFERENCES}

1 Australian Institute of Health and Welfare. Aboriginal and Torres Strait Islander adolescent and youth health wellbeing, 2018. Available: https://www.aihw.gov.au/getmedia/b40149b6-d133-4f16-a1e85a98617b8488/aihw-ihw-202.pdf.aspx?inline=true

2 Finlay S, Wenitong M. Aboriginal community controlled health organisations are taking a leading role in COVID-19 health communication. Aust N Z J Public Health 2020;44:251-2.

3 Miller A, Durrheim ADN, Aboriginal and Torres Strait Islander Community Influenza Study Group. Aboriginal and Torres Strait Islander communities forgotten in new Australian National Action Plan for Human Influenza Pandemic: "Ask us, listen to us, share with us". Med J Aust 2010;193:316-7.
4 Schütze H, Pulver LJ, Harris M. The uptake of Aboriginal and Torres Strait Islander health assessments fails to improve in some areas. Aust Fam Physician 2016;45:415.

5 HealthInfoNet. Summary of Aboriginal and Torres Strait Islander health. 229. NSW, 2017. https://healthinfonet.ecu.edu.au/ healthinfonet/getContent.php?linkid=609266\&title=Overview+of+ Aboriginal+and+Torres+Strait+Islander+health+status\%2C+2017

6 Peake RM, Jackson D, Lea J, et al. Meaningful engagement with Aboriginal communities using participatory action research to develop culturally appropriate health resources. $J$ Transcult Nurs 2021;32:129-36.

7 Power T, Kelly R, Usher K, et al. Living with diabetes and disadvantage: a qualitative, geographical case study. J Clin Nurs 2020;29:2710-22.

8 Braun V, Clarke V. Thematic analysis: a reflexive approach. University of Auckland, 2019. https://www. psych. auckland. ac. nz/en/about/ thematic-analysis. html

9 Nicholls R. Research and Indigenous participation: critical reflexive methods. Int J Soc Res Methodol 2009;12:117-26.

10 Geia LK, Hayes B, Usher K. Yarning/Aboriginal storytelling: towards an understanding of an Indigenous perspective and its implications for research practice. Contemp Nurse 2013;46:13-17. 
Correction: Influence of COVID-19 on the preventive health

behaviours of indigenous peoples of Australia residing in new south Wales: a mixed-method study protocol

Usher K, Bhullar N, Sibbritt D, et al. Influence of COVID-19 on the preventive health behaviours of indigenous peoples of Australia residing in New South Wales: a mixed-method study protocol. BMJ Open 2021;11:e047404. doi: 10.1136/bmjopen2020-047404.

This article was previously published with an error.

- Indigenous People has been capitalised throughout the paper.

- Orcid ids of authors have been added.

- Contributors and Patient and public involvement statements in the endnotes have been updated.

Open access This is an open access article distributed in accordance with the Creative Commons Attribution Non Commercial (CC BY-NC 4.0) license, which permits others to distribute, remix, adapt, build upon this work non-commercially, and license their derivative works on different terms, provided the original work is properly cited, appropriate credit is given, any changes made indicated, and the use is non-commercial. See: http://creativecommons.org/licenses/by-nc/4.0/.

(C) Author(s) (or their employer(s)) 2021. Re-use permitted under CC BY-NC. No commercial re-use. See rights and permissions. Published by BMJ.

BMJ Open 2021;11:e047404corr1. doi:10.1136/bmjopen-2020-047404corr1

A) Check for updates 